\title{
C-reactive protein levels do not correlate with retinal artery occlusion but with atherosclerosis
}

\begin{abstract}
Purpose To determine C-reactive protein (CRP) levels in acute retinal artery occlusion (RAO) and their association with atherosclerotic risk factors.

Methods CRP levels in 16 patients with RAO were compared with levels in 16 age-matched controls at risk of atherosclerosis and 16 young volunteers. Repeated CRP testing was performed 6 years later.

Results Elevated CRP levels ( $>3 \mathrm{mg} / \mathrm{l}$ ) and risk factors for atherosclerosis were detected in seven patients in the study group (44\%) and nine at-risk controls ( $56 \%$ ). On follow-up, CRP levels were reduced in all seven retested patients. Six patients died of vascular events within 5 years, of whom four had high CRP levels during RAO.

Conclusions CRP level correlates with atherosclerosis but it is not significantly elevated in patients with RAO.

Eye (2009) 23, 785-790; doi:10.1038/eye.2008.159; published online 6 June 2008
\end{abstract}

Keywords: atherosclerosis; C-reactive protein; retinal artery occlusion; survival

\section{Introduction}

The assumption that inflammation plays a pathogenetic role in atherosclerosis ${ }^{1-5}$ is supported by the similar histological features of the two conditions. ${ }^{1,2}$ The earliest lesion in the arterial wall, the fatty streak, consists of monocyte-derived macrophages and T lymphocytes. ${ }^{6-8}$ Each type of lesion characteristic of atherosclerosis apparently represents a different stage of the chronic inflammatory process in the arterial wall. ${ }^{6}$
N Goldenberg-Cohen ${ }^{1,2}$, Y Cohen ${ }^{3}$, Y Monselise ${ }^{4}$, I Eldar ${ }^{1}$, R Axer-Siegel ${ }^{1,2}$, D Weinberger ${ }^{1,2}$ and M Kramer ${ }^{1,2}$
${ }^{1}$ Department of Ophthalmology, Rabin Medical Center, Beilinson Campus, Petah Tiqwa, Israel

${ }^{2}$ Sackler Faculty of Medicine, Tel Aviv University, Tel Aviv, Israel

${ }^{3}$ Department of Gynecology, Cancer Research Center, Sheba Medical Center, Tel Hashomer, Israel

${ }^{4}$ Clinical Immunology Laboratory, Rabin Medical Center, Beilinson Campus, Petah Tiqwa, Israel

Correspondence: N Goldenberg-Cohen, Department of Ophthalmology, Schneider Children's Medical Center of Israel, Petah Tiqwa 49100, Israel Tel: + 97239376101 Fax: +972 39219084 . E-mail: ncohen1@ gmail.com

Received: 8 January 2008 Accepted in revised form: 24 April 2008 Published online: 6 June 2008 
Several studies have investigated the involvement of CRP in ocular diseases. Some reported that elevated CRP level was an independent risk factor for age-related macular degeneration ${ }^{34,35}$ as well as an indicator of its progression, ${ }^{36}$ although others failed to support these findings. ${ }^{37,38}$ Elevated CRP was also found to correlate positively with a diagnosis of arteritic anterior ischaemic optic neuropathy ${ }^{39,40}$ and with vascular conditions such as retinal vein occlusion ${ }^{41,42}$ and normal-tension glaucoma.$^{43}$ However, the value of CRP in patients with RAO has not yet been examined. We hypothesize that elevated serum levels of CRP are associated with acute $\mathrm{RAO}$ and might indicate higher future risk for vascular events.

The aims of this study were to determine whether CRP levels are increased in patients with acute RAO and to investigate the possible association of CRP with known risk factors of atherosclerosis and future systemic ischaemic events.

\section{Patients and methods}

The study group consisted of 10 men and 6 women of mean age $65 \pm 12$ years (range $43-85$ years) (Table 1 ). Four patients were less than 60 years old. The patients were treated immediately according to the local protocol (paracentesis and/or medications to lower intraocular pressure) and referred for systemic work-up for an embolic source, which consisted, in most cases, of blood analysis (complete blood count, sedimentation rate, and coagulation status), Doppler scan of the carotid arteries, and cardiac studies (including echography). Blood samples for CRP measurement were collected immediately following emergency treatment. All patients were prescribed aspirin. Repeated tests were performed in some patients 3-6 months later. In addition, for this study, the medical records of the patients were reviewed 6 years later, and the medical history and use of medications, especially aspirin or other nonsteroidal antiinflammatory drugs, were recorded. CRP levels were retested in the patients who could be located and made to agree. For the deceased patients, the cause and time of death were traced.

The findings were compared with two control groups: 16 age-matched candidates for elective cataract surgery, without RAO but with atherosclerotic risk factors, who had not taken aspirin for at least 7 days before the examination; and 16 young healthy volunteers.

All patients were treated for RAO at our clinic during the study period and the control subjects provided informed consent to participate before their inclusion in the study. The study was approved by the institutional Helsinki Committee.

\section{CRP test}

Blood samples were separated by centrifugation, and the sera were stored for simultaneous analysis at $-20^{\circ} \mathrm{C}$. CRP

Table 1 Demographic data and CRP levels for patients with acute retinal artery occlusion and at-risk age-matched control subjects

\begin{tabular}{|c|c|c|c|c|c|c|c|c|c|}
\hline \multirow[t]{3}{*}{ No } & \multicolumn{7}{|c|}{ Patients } & \multicolumn{2}{|c|}{ Control } \\
\hline & \multirow[t]{2}{*}{ Genderlage (years) } & \multirow[t]{2}{*}{$V A$} & \multirow[t]{2}{*}{$R A O$} & \multicolumn{3}{|c|}{$C R P(m g / l)$} & \multirow[t]{2}{*}{ Died } & \multirow{2}{*}{$\begin{array}{c}\text { Genderlage } \\
\text { (years) }\end{array}$} & \multirow{2}{*}{$\begin{array}{l}\text { CRP } \\
(m g / l)\end{array}$} \\
\hline & & & & First exam & FU 1 & End of FU & & & \\
\hline 1 & $\mathrm{M} / 85$ & FLP & C & 6.6 & - & - & $\dagger$ & $\mathrm{M} / 83$ & 5.2 \\
\hline 2 & $\mathrm{~F} / 71$ & ULP & $\mathrm{C}$ & 16 & - & 10.0 & $\dagger$ & $\mathrm{F} / 73$ & 5.1 \\
\hline 3 & $\mathrm{~F} / 64$ & $6 / 15$ & B & 7.8 & - & 5.0 & $\dagger$ & $\mathrm{F} / 66$ & 5.1 \\
\hline 4 & $\mathrm{~F} / 49$ & $1 / 24$ & C & $13.2^{\mathrm{a}}$ & $<0.1$ & $<0.1$ & 0 & $\mathrm{~F} / 50$ & 7.3 \\
\hline 5 & $\mathrm{M} / 75$ & $6 / 24$ & B & 7.9 & $<0.1$ & $<0.1$ & $\dagger$ & $\mathrm{M} / 75$ & 2.5 \\
\hline 6 & $\mathrm{M} / 77$ & ULP & $\mathrm{C}$ & $<0.1^{\mathrm{a}}$ & $<0.1$ & - & $\dagger$ & $\mathrm{M} / 65$ & 3.0 \\
\hline 7 & $\mathrm{M} / 71$ & $1 / 36$ & $\mathrm{C}$ & $1.2^{\mathrm{a}}$ & - & - & 0 & $\mathrm{M} / 80$ & 1.8 \\
\hline 8 & $\mathrm{~F} / 70$ & $6 / 10$ & B & $<0.1$ & - & - & 0 & $\mathrm{M} / 69$ & 2.0 \\
\hline 9 & $\mathrm{M} / 70$ & $1 / 24$ & B & $<0.1$ & $<0.1$ & - & 0 & $\mathrm{~F} / 73$ & $<0.1$ \\
\hline 10 & $\mathrm{M} / 60$ & FC & $\mathrm{C}$ & 3.9 & - & - & 0 & $\mathrm{M} / 76$ & 3.9 \\
\hline 11 & $\mathrm{~F} / 74$ & FLP & $\mathrm{C}$ & $<0.1$ & - & - & 0 & $\mathrm{~F} / 76$ & 11.0 \\
\hline 12 & $\mathrm{~F} / 73$ & $1 / 24$ & $\mathrm{C}$ & 3.2 & - & - & 0 & $\mathrm{~F} / 76$ & 7.3 \\
\hline 13 & $\mathrm{M} / 69$ & $6 / 30$ & B & $<0.1$ & $<0.1$ & - & $\dagger$ & $\mathrm{F} / 73$ & 11.3 \\
\hline 14 & $\mathrm{M} / 43$ & $6 / 10$ & B & $<0.1$ & $<0.1$ & - & 0 & $\mathrm{M} / 42$ & 0.9 \\
\hline 15 & $\mathrm{M} / 45$ & $6 / 20$ & B & $<0.1$ & $<0.1$ & - & 0 & $\mathrm{M} / 50$ & 5.0 \\
\hline 16 & $\mathrm{M} / 51$ & FLP & C & 2.8 & - & - & 0 & $\mathrm{M} / 51$ & 3.0 \\
\hline
\end{tabular}

VA- visual acuity; FLP- full light perception; ULP- uncertain light perception; FC- finger counting; RAO- retinal artery occlusion; B-branch; C-central. FU 1: 3-6 months after RAO; End of FU-end of follow-up.

${ }^{\mathrm{a} A s p i r i n}$ treated. 
levels were determined by nephelometry (Backman, Arra ${ }^{\circledR}$ Systems, Ireland). An elevated CRP level was defined as $>3 \mathrm{mg} / \mathrm{l}$.

\section{Statistical analysis}

$\chi^{2}$ or Fisher exact test was used to analyse the significance of differences in categorical variables between cases and controls; $t$-test or Mann-Whitney test was used for continuous variables.

\section{Results}

Seven patients had branch RAO and nine patients had central RAO. All patients with CRAO had severe visual loss $(1 / 24)$ or worse (Table 1$)$. Most patients with branch artery occlusion had moderate visual impairment, with acuity better than $6 / 30$, except one patient with macular branch involvement. Review of the medical history and work-up after the acute event revealed systemic conditions which are summarized in Table 2. None of the patients had clinical signs or symptoms of temporal arteritis. Three patients were receiving low-dose aspirin ( $100 \mathrm{mg} /$ day) at the time of the acute event, 12 were firsttime users, and 1 patient was receiving anticoagulation therapy with warfarin because of mitral valve replacement. None of the patients was being treated with corticosteroids.

Ten patients underwent Doppler examination of the carotid arteries. All had evidence of atherosclerosis; severe $(>70 \%)$ in three, moderate $(25-49 \%)$ in two, and minimal in five. In one patient, the diagnosis of severe carotid stenosis was made following the ocular event, and endarterectomy was performed. Echocardiography, performed in 14 patients ( 9 transesophageal), revealed valvular disease of different grades of severity in 5 of

Table 2 Atherosclerotic risk factors in patients with retinal artery occlusion and age-matched controls (candidates for cataract surgery)

\begin{tabular}{lrrrrr}
\hline Atherosclerotic disease & \multicolumn{3}{c}{ Patients $(\mathrm{n}=16)$} & Controls $(\mathrm{n}=16)$ & P-value \\
\cline { 2 - 5 } & $\mathrm{n}$ & $\%$ & $\mathrm{n}$ & $\%$ & \\
\hline Essential hypertension & 8 & 47 & 6 & 35 & NS \\
Ischaemic heart disease & 4 & 24 & 3 & 18 & NS \\
PAF & $3^{\mathrm{a}}$ & 18 & 1 & 6 & NS \\
TIA/CVA & 4 & 24 & 0 & 0 & 0.03 \\
Hyperlipidaemia & 4 & 24 & 3 & 18 & NS \\
Type II diabetes & 3 & 18 & 3 & 18 & NS \\
\hline
\end{tabular}

PAF: paroxysmal atrial fibrillation; TIA/CVA: transient ischaemic attack/ cerebrovascular accident.

aTwo patients had severe valvular heart disease; one had undergone mitral valve replacement and was being treated with anticoagulation drugs. them: 3-valve disease in two, 2-valve disease in two, 1 -valve disease in one.

Seven patients arrived for treatment within $6 \mathrm{~h}$ of clinical onset of RAO. Of the remainder, one arrived within $20 \mathrm{~h}$, and five arrived several days later; there were no accurate data for the other three patients.

The age-matched control group consisted of nine male and seven female subjects of mean age $67 \pm 12$ years (range 42-83 years). Their atherosclerotic risk factors included hypertension, ischaemic heart disease, hyperlipidemia, and type II diabetes mellitus, with no statistically significant differences from the study, except for history of cerebrovascular incidents, the presence being found in four patients and its absence in all the controls (Table 2). All subjects in this control group had been off aspirin for at least 1 week before CRP measurement, according to our local protocol for elective cataract surgery.

The young healthy control group with no atherosclerosis risk factors consisted of seven men and nine women of mean age $26 \pm 4.5$ years (range 20-32 years).

Elevated CRP levels ( $>3 \mathrm{mg} / \mathrm{l}$ ) were noted in seven patients $(44 \%)$ in the study group (Table 1 ), in nine subjects $(56 \%)$ in the age-matched control group (NS), and in none of the young control group. In comparison to these groups, none of the young healthy control group had elevated CRP levels $(P=0.025)$. Two of the three patients receiving aspirin at the time of the blood test had normal CRP levels. Adjustment for their presumed elevated levels without aspirin yielded a similar result to the control group (9/16 patients, 56\%).

Mean CRP level at the time of the event in the patient group was $4.4 \pm 4.8 \mathrm{mg} / 1$. Mean level in the age-matched control group with atherosclerotic risk factors was $4.7 \pm 3.2 \mathrm{mg} / \mathrm{l}$, and in the young healthy group, $1.3 \pm 0.6 \mathrm{mg} / 1$. A statistically significant difference in mean CRP level was calculated between the young control group and both the study group $(P=0.02)$ and the age-matched at-risk control group $(P<0.001)$.

CRP level was retested after 3-6 months of aspirin treatment in seven patients (Table 1). In two patients who had high levels at presentation, values dropped to normal; in the other five patients, levels remained undetectable.

All seven patients in the study group with increased CRP levels at presentation, and the two patients on aspirin treatment, had systemic risk factors for atherosclerosis, whereas the other seven patients with undetectable CRP levels did not $(P=0.002)$. CRP levels in the patients who had atherosclerotic risk factors were significantly higher than in patients who did not (mean $6.7 \pm 5.2$ vs $1.2 \pm 0.7 \mathrm{mg} / \mathrm{l}$, $P=0.003)$. 
Review of the medical records 6 years later revealed that 6 of the 16 study patients (four male, two female) had died at a mean interval of $3 \pm 2$ years (range 1 month to 5 years) from the acute vascular event. Mean age at death was $77 \pm 8.5$ years. Four of the six died of atherosclerosis-related causes (ischaemic heart disease, cerebrovascular accident): three had elevated CRP levels at the time of the RAO, and the fourth was receiving aspirin therapy at the time the event occurred. Three of the deceased patients underwent repeated CRP measurements at various times before death: levels were elevated in two (10 and $5 \mathrm{mg} / \mathrm{l}$ ) and undetectable in one. Seven of the 10 remaining patients had a low CRP level at the time of the acute event. The one patient who survived and had an elevated CRP level at the time of the RAO was retested 6 months later and was found to have an undetectable level (Table 1).

\section{Discussion}

In our study, mean CRP levels were found to be significantly elevated in both the patient group and the age-matched control group with atherosclerotic risk factors compared to the young subjects. These findings seem to indicate that high CRP levels may be associated with a risk of atherosclerosis and future risk of a lifethreatening vascular event. CRP correlated only with atherosclerosis and was not significantly elevated in patients with RAO. This observation is in agreement with the literature. ${ }^{24,44}$

Previous studies have attributed increased levels of CRP to the underlying inflammatory process in atherosclerosis, ${ }^{3,5,16,45-47}$ ischaemic events, such as myocardial infarct, ${ }^{13-18,26}$ and cerebrovascular accident. ${ }^{16,19,23}$ We focused on another atherosclerotic complication, RAO, a devastating cause of blindness. Despite our small patient sample compared to the other studies, which included thousands of patients, the findings were similar; that is, the majority of patients with one or more atherosclerotic risk factor had increased CRP levels. Furthermore, only the patients with known risk factors for atherosclerosis had increased CRP levels, whereas patients without these risk factors did not (Table 2). The latter group had increased risk factors for embolic RAO, such as severe valvular disease and atrial turbulent flow, patent foramen ovale, and aortic arch atheroma. $^{30,31}$

Most of the patients in this study were not receiving aspirin at the time of the acute event. When analysing the possible association between atherosclerosis and CRP levels, we found that all patients with elevated CRP had atherosclerosis risk factors, as well as the two patients who were being treated with aspirin and did not have elevated CRP levels at the time of the event.
Nevertheless, the mean CRP level in all patients with atherosclerosis risk factors was significantly higher than the level in patients without these risk factors. We did not limit our sample to non-aspirin-treated patients from the outset because of the rarity of the RAO, and because all the patients were treated by aspirin after the event, and we repeated the CRP measurements during follow-up.

Some of our patients with high CRP levels at the time of the acute event had reduced or even undetectable levels on retesting months or years later. This reduction was probably explained at least in part by the initiation of aspirin treatment. In addition, two of the three patients already receiving aspirin treatment before the event had low CRP levels at presentation despite the presence of atherosclerotic risk factors. Aspirin is administered to patients with arterial ischaemic disease mainly because of its antithrombotic effect. ${ }^{25}$ It exerts a potent antiinflammatory activity and is known to lower the level of CRP in chronic inflammatory states. ${ }^{48}$ Thus, the drop in CRP levels following aspirin treatment in our study may suggest a poor prognostic value of persistently high CRP levels for future ischaemic events..$^{20,26,47-50}$

The two patients with initially high levels who were not retested (both refused) had other ischaemic events at 1 month to 2 years after the RAO (cerebrovascular accident, myocardial infarction, and fatal disseminated intravascular coagulation). Although there is no known relationship of CRP level during acute RAO and later fatal ischaemic events, one study has reported an association of CRP and long-term mortality in patients with unstable coronary artery disease. ${ }^{20}$ Our file review conducted 6 years after the occlusive event revealed that six patients had died of atherosclerosis-related causes, of whom four had elevated CRP levels at the time of the event. By contrast, of three of the nine survivors who had elevated CRP levels, one had undetectable levels few months later. These findings are in contrast to the report of De Potter and Zografos, ${ }^{51}$ who failed to find an association between survival and RAO. Furthermore, in the latter study, a worse prognosis was found for patients with visible emboli, and not for patients with atheromatous carotid disease.

Interestingly, the increase in CRP levels occurred independently of the severity of the occlusion (complete or partial branch RAO), and no correlation was found between CRP levels and time from the acute RAO event to blood sampling. Although such correlations have been found for CRP levels in other ischaemic conditions, ${ }^{52}$ there is probably lack of mass effect in a small organ such as the eye.

This study has some limitations. The patient group was small, with some variations among medical history and background diseases. This factor also limited the possibility to evaluate the significance of CRP levels as an 
inflammatory marker. However, considering the rarity of RAO, the study group is relatively large. Furthermore, as mentioned, some of the patients were treated with aspirin before the acute RAO event. Less than half the patients underwent repeated examinations, and six patients had died within 5 years of follow-up.

Nevertheless, to the best of our knowledge, this is the first study to compare CRP levels and atherosclerosis risk factors between patients with RAO and two different control groups, and the findings are in agreement with other studies in larger populations with other complications of atherosclerosis. We also believe it is the first contemporary study, to summarize the long-term follow-up findings in this unique patient group in terms of CRP levels.

The significance of CRP in RAO is probably associated with the atherosclerotic risk factors underlying the disorder. However, some patients demonstrate elevated levels following the ischaemic event, so a further elevation during acute RAO cannot be ruled out. The relationship of CRP to atherosclerosis is also supported by the larger proportion of deaths among the patients with RAO and elevated CRP.

\section{Acknowledgements}

This study was presented in part at the Annual Meeting of the Association for Research in Vision and Ophthalmology (ARVO), Fort Lauderdale, FL, USA, 2001; Abstract no. 3064; supported by the Ernest and Nusia Gothalf Fund, Tel Aviv University, 1998. We thank Ms. Dorit Karesh for the statistical analysis and Gloria Ginzach, Marian Propp and Melanie Kawe for their editorial and secretarial assistance.

\section{References}

1 Ross R. Atherosclerosis is an inflammatory disease. Am Heart J 1999a; 138: S419-S420.

2 Blum A, Miller HI. The role of inflammation in atherosclerosis. Isr J Med Sci 1996; 32: 1059-1065.

3 Ludewig B, Zinkernagel RM, Hengartner H. Arterial inflammation and atherosclerosis. Trends Cardiovasc Med 2002; 12: 154-159.

4 Williams KJ, Tabas I. Atherosclerosis and inflammation. Science 2002; 297: 521-522.

5 Farmer JA, Torre-Amione G. Atherosclerosis and inflammation. Curr Atheroscler Rep 2002; 4: 92-98.

6 Ross R. Atherosclerosis - an inflammatory disease. N Engl J Med 1999b; 340: 115-126.

7 Bhakdi S. Pathogenesis of atherosclerosis: infection versus immune pathogenesis. A new concept. Herz 2000; 25: 84-86.

8 Maseri A. Inflammation, atherosclerosis, and ischemic events - exploring the hidden side of the mood. $\mathrm{N} \mathrm{Engl} \mathrm{J}$ Med 1997; 336: 1014-1016.
9 Cleland SJ, Sattar N, Petrie JR, Forouhi NG, Elliott HL, Connell JM. Endothelial dysfunction as a possible link between C-reactive protein levels and cardiovascular disease. Clin Sci (Colch) 2000; 98: 531-535.

10 Du Clos TW. Function of C-reactive protein. Ann Med 2000; 32: 274-278.

11 Ohzato H, Yoshizaki K, Nishimoto N, Ogata A, Tagoh H, Monden $\mathrm{M}$ et al. Interleukin- 6 as a new indicator of inflammatory status: detection of serum levels of interleukin-6 and C-reactive protein after surgery. Surgery 1992; 111: 201-209.

12 Gabay C, Kushner L. Acute phase proteins and other systemic responses to inflammation. N Engl J Med 1999; 340: 448-454.

13 de Beer FC, Hind CR, Fox KM, Allan RM, Maseri A, Pepys MB. Measurement of C-reactive protein concentration in myocardial ischemia and infarction. $\mathrm{Br}$ Heart J 1982; 47: 239-243.

14 Liuzzo G, Baisucci LM, Gallimore JR, Caligiuri G, Buffon A, Rebuzzi AG et al. Enhanced inflammatory response in patients with preinfarction unstable angina. J Am Coll Cardiol 1999; 34: 1696-1703.

15 Fichtlscherer S, Rosenberger G, Walter DH, Breuer S, Dimmeler S, Zeiher AM. Elevated C-reactive protein levels and impaired endothelial vasoreactivity in patients with coronary artery disease. Circulation 2000; 102: 1000-1006.

16 Ridker PM. C-reactive protein and risks of future myocardial infarction and thrombotic stroke. Eur Heart J 1998; 19: 1-3

17 Ridker PM, Glynn RJ, Hennekens CH. C-reactive protein adds to the predictive value of total and HDL cholesterol in determining risk of first myocardial infarction. Circulation 1998b; 97: 2007-2011.

18 Wijns W, Ribichini F. CRP: does it stand for coronary restenosis prediction? Eur Heart J 2000; 21: 1121-1123.

19 Gussekloo J, Schaap MC, Frölich M, Blauw GJ, Westendorp RG. C-reactive protein is a strong but nonspecific risk factor of fatal stroke in elderly persons. Arterioscler Thromb Vasc Biol 2000; 20: 1047-1051.

20 Lindahl B, Toss H, Siegbahn A, Venge P, Wallentin L. Markers of myocardial damage and inflammation in relation to long-term mortality in unstable coronary artery disease. FRISC Study Group. Fragmin during instability in coronary artery disease. N Engl J Med 2000; 343: 1139-1147.

21 Majewski W, Laciak M, Staniszewski R, Górny A, Mackiewicz A. C-reactive protein and alpha-1-acid glycoprotein in monitoring of patients with acute arterial occlusion. Eur J Vasc Surg 1991; 5: 641-645.

22 Majewski W, Zielinski A, Laciak M, Staniszewski R, Górny A, Zapalski $S$ et al. C-reactive protein and alpha-1-acid glycoprotein in monitoring of patients with chronic arterial occlusion of the lower limbs. Eur J Vasc Surg 1993; 7: 628-632.

23 Blann Ad, Ridker PM, Lip GY. Inflammation, cell adhesion molecules, and stroke: tools in pathophysiology and epidemiology? Stroke 2002; 33: 2141-2143.

24 Kinlay S, Egido J. Inflammatory biomarkers in stable atherosclerosis. Am J Cardiol 2006; 4, 98 2P-8P.

25 Ridker PM, Cushman M, Stampfer MJ, Tracy RP, Hennekens $\mathrm{CH}$. Inflammation, aspirin and the risk of cardiovascular disease in apparently healthy men. N Eng J Med 1997; 336: 973-979.

26 Blaschke F, Bruemmer D, Yin F, Takata Y, Wang W, Fishbein $\mathrm{MC}$ et al. C-reactive protein induces apoptosis in human 
coronary vascular smooth muscle cells. Circulation 2004; 110 579-587.

27 Kimura K, Hashimoto Y, Ohno H, Uchino M, Ando M. Carotid artery disease in patients with retinal artery occlusion. Intern Med 1996; 35: 937-940.

28 Kramer M, Goldenberg-Cohen N, Shapira Y, Axer-Siegel R, Shmuely H, Adler Y et al. Role of transesophageal echocardiography in the evaluation of patients with retinal artery occlusion. Ophthalmology 2001; 108: 1461-1464.

29 Kinlay S, Timms T, Clark M, Karam C, Bilodeau T, Ridker PM et al. Comparison of effect of intensive lipid lowering with atorvastatin to less intensive lowering with lovastatin on C-reactive protein in patients with stable angina and inducible myocardial ischemia. Am J Cardiol 2002; 89: 1205-1207.

30 Foroozan R, Savino PJ, Sergott RC. Embolic central retinal artery occlusion detected by orbital color Doppler imaging. Ophthalmology 2002; 109: 744-747. (Discussion 747-748).

31 Larsson J. Central retinal artery occlusion in a patient homozygous for factor V Leiden. Am J Ophthalmol 2000; 129: 816-817.

32 Greven CM, Slusher MM, Weaver RG. Retinal artery occlusion in young adults. Am J Ophthalmol 1995; 120: 776-783.

33 Kramer M, Goldenberg-Cohen N, Axer-Siegel R, Weinberger D, Cohen Y, Monselise Y. Inflammatory reaction in acute retinal artery occlusion: cytokine levels in aqueous humor and serum ocular immunology and inflammation. Occul Immunol Inflamm 2005; 13: 305-310.

34 Seddon JM, Gensler G, Milton RC, Klein ML, Rifai N. Association between $\mathrm{C}$-reactive protein and age-related macular degeneration. JAMA 2004; 291: 704-710.

35 Vine AK, Stader J, Branham K, Musch DC, Swaroop A. Biomarkers of cardiovascular disease as risk factors for age-related macular degeneration. Ophthalmology 2005; 112: $2076-2080$.

36 Seddon JM, George S, Rosner B, Rifai N. Progression of age-related macular degeneration: prospective assessment of C-reactive protein, interleukin-6, and other cardiovascular biomarkers. Arch Ophthalmol 2005; 123: 774-782.

37 Dasch B, Fuhs A, Behrens T, Meister A, Wellmann J, Fobker $\mathrm{M}$ et al. Inflammatory markers in age-related maculopathy: cross-sectional analysis from the Muenster Aging and Retina Study. Arch Ophthalmol 2005; 123: 1501-1506.

38 McGwin G, Hall TA, Xie A, Owsley C. The relation between $\mathrm{C}$-reactive protein and age-related macular degeneration in the Cardiovascular Health Study. Br J Ophthalmol 2005; 89: 1166-1170.

39 Parikh M, Miller NR, Lee AG, Savino PJ, Vacarezza MN, Cornblath $\mathrm{W}$ et al. Prevalence of a normal C-reactive protein with an elevated erythrocyte sedimentation rate in biopsy-proven giant cell arteritis. Ophthalmology 2006; 113 1842-1845.

40 Costello F, Zimmerman MB, Podhajsky PA, Hayreh SS. Role of thrombocytosis in diagnosis of giant cell arteritis and differentiation of arteritic and non-arteritic anterior ischemic optic neuropathy. Eur J Ophthalmol 2004; 14: $245-257$

41 Dodson PM, Shine B. Retinal vein occlusion: C-reactive protein and arterial hypertension. Acta Ophthalmol (Copenh) 1984; 62: 123-130.

42 Lee HB, Pulido JS, McCannel CA, Buettner H. Role of inflammation in retinal vein occlusion. Can J Ophthalmol 2007; 42: 131-133.

43 Leibovitch I, Kurtz S, Kesler A, Feithliher N, Shemesh G, Sela BA. C-reactive protein levels in normal tension glaucoma. J Glaucoma 2005; 14: 384-386.

44 Cao JJ, Arnold AM, Manolio TA, Polak JF, Psaty BM, Hirsch $\mathrm{CH}$ et al. Association of carotid artery intima-media thickness, plaques, and C-reactive protein with future cardiovascular disease and all-cause mortality: the Cardiovascular Health Study. Circulation 2007; 3, 116 32-38.

45 Ridker PM, Cushman M, Stampfer MJ, Tracy RP, Hennekens $\mathrm{CH}$. Plasma concentration of C-reactive protein and risk of developing peripheral vascular disease. Circulation 1998a; 97: $425-428$

46 Ridker PM. Inflammation, atherosclerosis, and cardiovascular risk: an epidemiologic view. Blood Coagul Fibrinolysis 1999; 10(suppl 1): S9-S12.

47 Ridker PM, Hennekens CH, Buring JE, Rifai N. C-reactive protein and other markers of inflammation in the prediction of cardiovascular disease in women. N Engl J Med 2000a; 342: 836-843.

48 Fiotti N, Giansante C, Ponte E, Delbello C, Calabrese S, Zacchi T et al. Atherosclerosis and inflammation. Patterns of cytokine regulation in patients with peripheral arterial disease. Atherosclerosis 1999; 145: 51-60.

49 Mosca L. C-reactive protein - to screen or not to screen? N Engl J Med 2002; 347: 1615-1617.

50 Ridker PM, Rifai N, Stampfer MJ, Hennekens CH. Plasma concentration of interleukin- 6 and the risk of future myocardial infarction among apparently healthy men. Circulation 2000b; 101: 1767-1772.

51 De Potter P, Zografos L. Survival prognosis of patients with retinal artery occlusion and associated carotid artery disease. Graefe's Arch Clin Exp Ophthalmol 1993; 231: 212-216.

52 Tomoda H, Aoki N. Prognostic value of C-reactive protein levels within six hours after the onset of acute myocardial infarction. Am Heart J 2000; 140: 324-328. 